\title{
The Reform of Capstone Course of Financial Undergraduate Thesis based on the Application of Econometrics
}

\author{
Lianzhu Peng ${ }^{1,2, a}$, Jing $\mathrm{Yu}^{1,}$, , Shijing Zhan ${ }^{3,4, c, ~ *}$ \\ ${ }^{1}$ School of accounting and finance, Beijing Institute of Technology, Zhuhai, China \\ ${ }^{2}$ School of economics, Jilin University, Changchun, China \\ ${ }^{3}$ School of Materials and Environment, Beijing Institute of Technology, Zhuhai, China \\ ${ }^{4}$ Zhuhai Topsun Electronic Technology Co., Ltd, Zhuhai, China \\ a7876419@qq.com, bjingabd83@163.com, c, *zhanshijing@163.com
}

\begin{abstract}
In order to improve the quality of undergraduate thesis of the financial majors, the capstone course was introduced based on the application of Econometrics. In this paper the concept of capstone course was introduced and the reform of the undergraduate thesis based on the Capstone system was designed and implemented. A reasonable capstone system scheme according to the established curriculum objectives and the ability quality to be cultivated was designed, the whole process of the project implementation was managed. The teaching goal of process oriented and comprehensive ability training has been achieved and the teaching effect has been improved.
\end{abstract}

Keywords: Capstone Course; Undergraduate Thesis; Reform; Econometrics Application.

\section{Introduction}

Undergraduate thesis is an important part of undergraduate teaching plan. It is designed to test students' ability of integrating their knowledge and practice that they have learned in the past and their ability of recognizing, analyzing and solving problems in the research topic. [1,2] However, with the rapid expansion of university, the amount of students grows rapidly, the condition of more students and fewer teachers exists popular in the financial majors.

The high ratio of students to teachers and the influence of improper study style and academic misconduct results the quality of undergraduate thesis. The problems in the traditional mode of financial undergraduate thesis were analyzed and the capstone course was introduced into the financial thesis based on the application of Econometrics in this paper.

\section{Problems of the Present Undergraduate Thesis}

\subsection{The High Ratio of Students to Teachers}

Each teacher usually needs to undertake the guidance work of more than ten undergraduate students' graduation thesis, and at the same time, they also have to undertake the teaching work of other courses. On the other hand, the students are also faced with the problems of finding jobs and leaving school for internship, and there is not much time to meet with the tutors to discuss the writing of graduation thesis. Therefore, one of the reasons for the low quality of graduation thesis is that teachers do not give enough guidance to students and students do not consult their teachers frequently.

Each teacher should guide their students to choose different topics, which required teachers' high academic ability and guidance level. But the research specialty, time and energy of teacher is limited and it is impossible to cover all aspects of major. So, guiding students to write a series of sub topics of the same big topic is better to write so many topics.

\subsection{The Repetitive Research Topics}

In some colleges, sometimes there is a topic which was repeatedly selected by several students of different grades, or even by more than one student of the same class, and the content of the same topic 
may be similar without any innovative. There would be a lot of citation, repetition of low-level, lack of self-awareness and innovation.

Although the requirements for innovation of undergraduate thesis are not high, with the development of society and economic reform, many new economic problems and management problems emerge. In addition, with the demand for the cultivation of applied undergraduate talents, the thesis of economic undergraduates should keep pace with the times and innovate constantly to meet the needs of social and economic development.

\subsection{The Low Quality Papers Because of the Plagiarism and Patchwork}

At present, plagiarism and patchwork are serious problems for many colleges. Although some methods such as duplicate checking, plagiarism and demerit recording were taken to deter students for plagiarism and patchwork, and severely punish academic plagiarism and counterfeiting, which greatly curbs academic misconduct, it does not fundamentally solve the problems.

Students often use the methods of adjusting sentence structure and modifying the expression mode to lower their papers' repetition rate. Therefore, these deterrence measures are still a temporary solution to the problems of plagiarism and plagiarism.

There may be several reasons for the low quality papers. First, the topics are theoretical and improper for students. Theoretical research is boring and much harder than the applied research for undergraduate students, and their poor knowledge reserve and weak research ability prevent them from completing such theoretical topics. In order to finish their thesis, some students may copy and piece together the others' academic appoints. In the process of practice, we found that the more theoretical the research topic, the higher the repetition rate, which can verify this view to some extent.

Second, due to the lack of production and social practice, college students do not have a good understanding of the topics, they just analyze and solve the problems in their unpractical way. As a result, in the process of finishing their thesis, they often repeat the work of others at a low level, and be out of touch with the actual problems.

Third, the duplicate checking system of the university can't judge the quality of their thesis. The original intention of undergraduate thesis is to systematically sort out and summarize the theoretical knowledge and integrate knowledge and skills learned in the colleges, and to enhance students' abilities to identify, analyze, and solve real world problems.

Actually, the situation deviated from the original intention. Especially for the application-oriented colleges and universities, most students will get into the enterprises after graduation, so the graduation thesis would be their final lesson connecting to their profession, and should be closely related to the professional and social practice.

At present, the paper assessment mode has some disadvantages because the papers deviate from the reality and lack of teamwork skills.

The traditional graduation thesis model has not adapted to the rapid development of the economic situation and social environment for talent training requirements, it is necessary to reform the system and mode. In view of the above problems, in the operation of the graduation thesis of financial undergraduate, we design a set of scheme that can assess the theoretical knowledge, professional skills, problem analysis, problem-solving and research literacy of students, combining with the concept and guidelines of Applied Undergraduate Talents Training and the characteristics of corresponding disciplines.

\section{Reform of Capstone Course of Financial Undergraduate Thesis}

\subsection{The Concept and Application of Capstone Course}

Undergraduate education in the United States includes a capstone course at the conclusion of each program of study $[3,4]$. These capstone courses are designed to bring together the concepts learned during 4 years of higher education and range from formal, structured papers to performance of a set of activities related to the student's major [4]. 
It establishes a more meaningful connection between professional learning and professional experience, and builds a bridge for students to transition from school to workplace.[5]

In practice, there are two kinds of application of capstone course: project-based and research-based. The main goal of project-based Capstone course design is to apply theory to practice, and to integrate the knowledge learned through the operation of open-ended project. This operation is often used in engineering colleges and universities in the United States. The research-based Capstone course design is mainly in academic research, based on a large research topic or research direction, based on the corresponding theory to extend, expand, in-depth, by a sub topic stitching together, constitute a complete large topic research results. [6,7]

General academic universities or research institutions can adopt this design paradigm.

No matter what kind of capstone course design, students can integrate and use the knowledge they have learned in practice or research, so as to realize the smooth transition from theoretical classroom to work practice or research application. It has the characteristics of top-level, transitional, comprehensive and practical.

\subsection{Graduation Thesis System Design based on the Concept of Capstone Course}

Based on the concept of capstone course and aiming at the disadvantages of undergraduate thesis of finance, Zhuhai Campus of Beijing Institute of Technology (BITZH) introduces capstone course to reform of undergraduate thesis, designs a set of scientific and reasonable operation scheme and evaluation system, improves the quality of undergraduate thesis, and can evaluate students' comprehensive ability and professional theory completely.

The specific scheme design is as follows:

First, according to the specialty characteristics of the students, combined with the talent training program of the major, the paper designs the system scheme of graduation thesis, including organization system, management system, implementation scheme, evaluation standard, supervision system, etc. For example, taking the credit management major of BITZH finance department as an example, according to the characteristics and the talent training objectives of credit management specialty, the social demand for credit management professionals, and the planning of students after graduation, two types of graduation thesis capstone projects are designed: the project based on academic research and the project based on employment. Different types of capstone projects design are corresponding to training objectives and assessment capabilities, establishing project teams involved, selecting appropriate research topics.

In the practical process, considering the theoretical and research level of undergraduates, it is required that the results of research projects based on academic research or employment must be empirical papers or research papers. Therefore, students are encouraged to use econometric theories and methods as main technologies to guide research and operate projects. For credit management major, if it is a summit project based on academic research, combined with professional characteristics, students are required to do empirical analysis, such as credit risk research for commercial banks or credit risk research for real estate industry; if it is a summit project based on employment (practice), students are required to conduct field research, sampling, analysis and design specific work For example, research on the credit risk management of P2P network credit or the credit status of college students. The application of econometrics was one of the most important content in the thesis.

Second, each instructor, combined with his own research direction and professional field, chooses a large research topic and establishes a capstone project team. This year's graduates take the way of two-way selection, choose tutors (projects), join the project group, and become members of the summit project group. Under the capstone project group, taking the research topic as the center, the mind mapping is applied to further extend and expand, and sub topics of research and corresponding project units were generated. Fig. 1 shows that, if a tutor's research direction is credit rating, then credit rating is the central theme (root node) of mind mapping, sub topics such as "national credit rating" (A),"enterprise credit rating" (B), "financial institution credit rating" (C) are generated. And 
under the sub topics of "enterprise credit rating"(B), according to different credit rating methods, it can be divided into "logical regression method enterprise credit rating" (B1), " KMV method enterprise credit rating " (B2), " enterprise credit rating by classification tree " (B3) and so on. Among them, the first level project team is an independent operation unit, which is composed of no more than three graduate teams with team leaders; each team member is responsible for the sub projects of the next level (Level II project team), and can bring a junior or sophomore assistant to form the inheritance of research or project.

Third, for all levels of projects, the overall planning and detailed design of the project are carried out. It includes the research outline of the project theme, the objectives of training and assessment, the division of work in the implementation of the project, the tasks of each member, the research process, and the performance evaluation criteria.

Finally, according to the established research plan, the implementation of the project is assessed and recorded according to the time node, as part of the basis of the final performance evaluation. After the completion of the whole project, according to the results of the project graduation thesis and the performance of team members in the whole process of the project, the thesis and individual are evaluated and summarized according to the assessment standards.

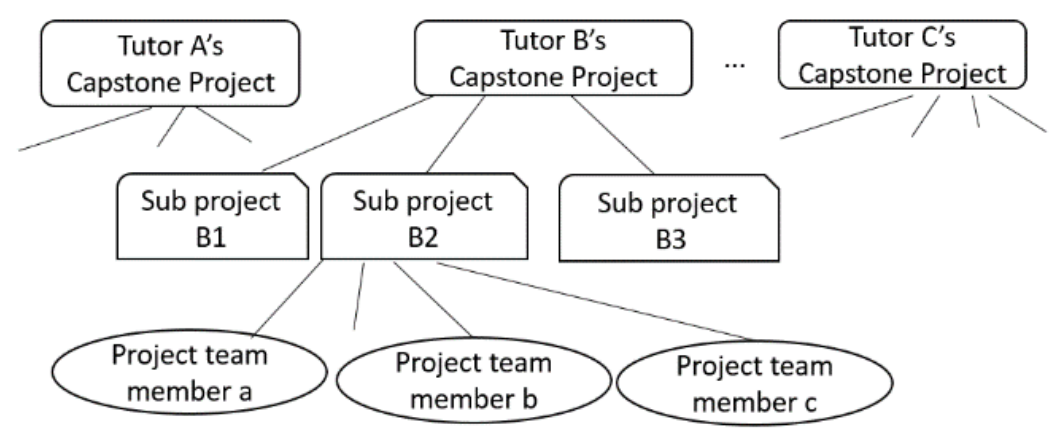

Fig 1. Organizational structure of Capstone Undergraduate Thesis

\subsection{Implementation and Assessment}

In the graduation thesis reform plan of College of accounting and finance in BITZH, the design, implementation, management and assessment of the scheme are carried out according to the abovementioned capstone project system theory.

Among them, in the process of management and control, the team leader of the first level project team is responsible for the division and management of the project paper group, and submits relevant materials on behalf of the project team. During the completion of graduation thesis, the members of the project team shall record the work content according to the division, and the instructor shall make guidance record as part of the basis for the final evaluation of each student.

After the paper is completed, the first level project team shall provide a report on the division and contribution (percentage) of each member. The report must be confirmed by all project team members. The division and contribution degree are part of individual performance evaluation.

In the part of achievement evaluation, the quality of the paper, the division and contribution of individuals and the spirit of teamwork are comprehensively investigated. The paper guidance records, team members' work content records, signed and confirmed members' division and contribution report are used as the evaluation factor of team cooperation and individual contribution. The evaluation criteria of individual performance are shown in Table 1.

In addition, in order to cultivate the teamwork spirit of students, there are two factors should be emphasized. One factor is that if the result of the group evaluation is failed, all members in the group will fail; the other factor is that if the member in the group has no contribution to the teamwork, he will fail no matter of the condition of their papers.

To sum up, during the implementation of the project, according to the training objectives and assessment ability requirements designed in advance, the whole process assessment is implemented, 
and special attention is paid to the cultivation of students' team spirit and ability. It not only takes into account the requirements of project research integration, but also evaluates the individual ability and quality, realizing the cultivation of students' comprehensive ability.

Table 1. The evaluation in the Capstone system of undergraduate thesis

\begin{tabular}{|c|c|c|c|}
\hline Factor & Scoring index & Graders & Proportion (\%) \\
\hline \multirow{2}{*}{$\begin{array}{c}\text { Evaluation of the } \\
\text { results }\end{array}$} & Thesis & Instructor & 32 \\
\cline { 2 - 4 } & Thesis & Review teachers & 16 \\
\hline $\begin{array}{c}\text { Personal } \\
\text { contribution }\end{array}$ & $\begin{array}{c}\text { Thesis defense } \\
\text { content, Division and Contribution in teamwork }\end{array}$ & $\begin{array}{c}\text { Instructor, } \\
\text { teammates }\end{array}$ & 15 \\
\hline Score in team work & $\begin{array}{c}\text { Record of paper guidance, Record personal } \\
\text { content, Division and Contribution in teamwork }\end{array}$ & $\begin{array}{c}\text { Instructor, } \\
\text { teammates }\end{array}$ & 5 \\
\hline
\end{tabular}

\subsection{Evaluation of Capstone Course}

After the initial partial professional development and the comprehensive promotion after the mature operation, the capstone project graduation thesis reform of BITZH has been operated for three times and achieved good results. Some problems of the above graduation thesis have been improved.

First, the paper title has the degree of identification, and the number of similar topics is reduced. After writing a paper in a group of one questions, the number of similar topics is reduced and the paper is more recognizable. To some extent, we should prevent the phenomenon of mutual plagiarism.

Second, due to the different topics, there are less similarities in the content of the paper, and the research methods and perspectives show a pattern of blooming flowers.

Third, the quality of papers has been improved to a certain extent compared with previous years, and the number of papers with poor scores (below 70 points) has decreased.

Fourth, teachers are more serious in the guidance, evaluation and defense of the paper. At the same time, the number of teachers can focus on more detailed guidance and evaluation of papers, with the same score as in previous years, the quality of a single paper has improved.

Fifth, the quality of excellent papers has been improved. The characteristics of group operations are that they can work together to challenge more difficult research topics and research methods. As a result, the quality of excellent papers is higher than that in previous years.

\section{Conclusion}

Capstone course focuses on the practice of process oriented teaching concept. Based on the capstone project system, the whole process management and assessment is carried out from the establishment of research topics, project participation, team organization, project division, project implementation, sub project results summary, project results submission, thesis defense, thesis and personal performance evaluation. It is beneficial to develop the students' ability to analyze and solve problems in the whole field of study and practice based on the perspective of the tutor, and to integrate the research and practice of the students. Multidimensional evaluation can also make a comprehensive and objective assessment of students' performance. On the whole, it can stimulate students' initiative and improve the teaching effect of undergraduate thesis.

\section{Acknowledgments}

The financial supports from 2016 Undergraduate Economics Teaching Reform Project of Guangdong Provincial Education Department of (2016JJ013) are greatly appreciated. 


\section{References}

[1] Rao J.H., "Promoting the reform of undergraduate thesis mode". Laboratory research and exploration, Vol.3, 160-162, 2012.

[2] Collier, P.J., The effects of completing a capstone course on student identity. Sociology of Education, vol. 73, 285-299, 2000.

[3] Dorothy Y. Brockopp, Melanie Hardin-Pierce and J. Darlene Welsh, "An Agency-Financed Capstone Experience for Graduating Seniors", Journal of Nursing Education, Vol. 45(4), 137-140, April 2006.

[4] Todd R. H. and Magleby S. P., "Elements of a successful capstone course considering the needs of stakeholders". Eutopen Journal of Engineering Education, Vol. 30(2), 209- 212, May 2005.

[5] Jervis, K.J. and Hartley, C.A., "Learning to design and teach an accounting capstone". Issues in Accounting Education, Vol. 20 (4), 311- 339, 2005.

[6] Feng X.L, "Comparison and Enlightenment of graduation design between Chinese and American universities". Journal of Social Sciences of Jiamusi University, Vol. 3, 171-182, 2020.

[7] Liu X.Q. and Jiang X.F. "Curriculum reform under the quality strategy: the reform and development of the Capstone course of American undergraduate education since 1980s". Education Research of Tsinghua University, Vol. 02, 69-76, 2010. 